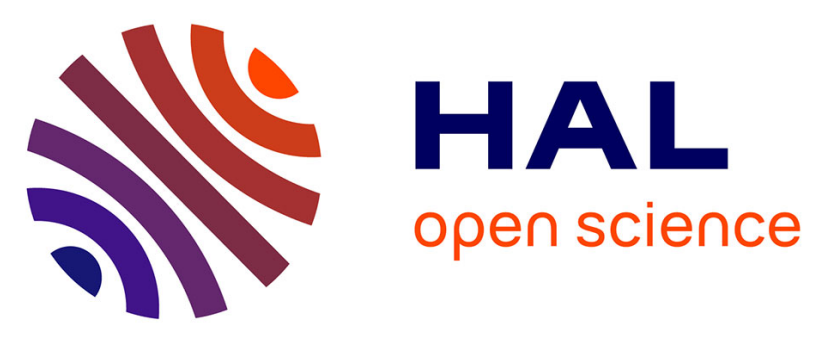

\title{
Electrochemically driven evolution of Br-containing aqueous solution composition
}

Mikhail M. Petrov, Dmitry V. Konev, Vitaly V. Kuznetsov, Anatoly E. Antipov, Artem T. Glazkov, Mikhail A. Vorotyntsev

\section{To cite this version:}

Mikhail M. Petrov, Dmitry V. Konev, Vitaly V. Kuznetsov, Anatoly E. Antipov, Artem T. Glazkov, et al.. Electrochemically driven evolution of Br-containing aqueous solution composition. Journal of Electroanalytical Chemistry, 2019, 836, pp.125 - 133. 10.1016/j.jelechem.2019.01.070 . hal-03485896

\section{HAL Id: hal-03485896 https://hal.science/hal-03485896}

Submitted on 20 Dec 2021

HAL is a multi-disciplinary open access archive for the deposit and dissemination of scientific research documents, whether they are published or not. The documents may come from teaching and research institutions in France or abroad, or from public or private research centers.
L'archive ouverte pluridisciplinaire HAL, est destinée au dépôt et à la diffusion de documents scientifiques de niveau recherche, publiés ou non, émanant des établissements d'enseignement et de recherche français ou étrangers, des laboratoires publics ou privés.

\section{다)(1) $(5$}

Distributed under a Creative Commons Attribution - NonCommerciall 4.0 International 


\title{
Electrochemically driven evolution of Br-containing aqueous solution composition
}

Mikhail M. Petrov ${ }^{\mathrm{a}, \mathrm{b}}$ *, Dmitry V. Konev ${ }^{\mathrm{a}, \mathrm{c}}$, Vitaly V. Kuznetsov ${ }^{\mathrm{a} *}$, Anatoly E. Antipov ${ }^{\mathrm{a}, \mathrm{b}}$, Artem T. Glazkov ${ }^{\mathrm{b}}$, Mikhail A. Vorotyntsev ${ }^{\mathrm{a}, \mathrm{b}, \mathrm{c}, \mathrm{d} *}$

${ }^{a}$ D.I. Mendeleev University of Chemical Technology of Russia, Moscow, Russia

${ }^{b}$ M.V. Lomonosov Moscow State University, Moscow, Russia

${ }^{c}$ Institute for Problems of Chemical Physics, Russian Academy of Sciences, Chernogolovka, Russia

${ }^{d}$ ICMUB, UMR 6302 CNRS-Université de Bourgogne, Dijon, France

\begin{abstract}
There exist numerous $\mathrm{Br}$-containing species in various oxidation states between -1 and $+5\left(\mathrm{Br}^{-}\right.$, $\mathrm{Br}_{3}^{-}, \mathrm{Br}_{5}^{-}, \mathrm{Br}_{2}$ in the solute and liquid states, $\mathrm{BrO}^{-}, \mathrm{HBrO}, \mathrm{BrO}_{3}^{-}$, etc.), which are mutually transformed via numerous protonation/deprotonation, chemical and redox/electrochemical processes. Composition of their aqueous solutions has been analyzed under conditions of thermodynamic equilibrium for various total concentrations of $\mathrm{Br}$ atoms inside the system, $c_{\text {tot }}$ $\left(0.2-2.0 \mathrm{Br}\right.$-atom mol dm${ }^{-3}$ ) as a function of $\mathrm{pH}$ (from 2 to 8 ) and electrode potential. $\mathrm{Br}^{-}$ anions are the dominant species at sufficiently negative electrode potentials while bromate anions are mostly present at high positive ones. Concentrations of the species in intermediate oxidation states existing within the medium potential range depend strongly on solution $\mathrm{pH}$. In neutral and alkaline solutions $(\mathrm{pH} \geq 6)$ the transformation between the limiting oxidation states, -1 and +5 , takes place in a relatively narrow interval of electrode potentials, relative fractions of intermediate Br-containing species being low. On the contrary, for more acidic solutions the width of this potential interval is becoming broader, and numerous species in intermediate oxidation states are dominant there. Under such conditions, the relative fractions of these intermediate species depend essentially on the total Br-atom concentration in all oxidation states, $c_{\text {tot }}$. Namely, tribromide anion, $\mathrm{Br}_{3}{ }^{-}$, and solute bromine, $\mathrm{Br}_{2}$, play the principal role for low $c_{\text {tot }}$ concentrations while the relative contribution of the liquid bromine, $\mathrm{Br}_{2}{ }^{\text {liq }}$, increases rapidly for higher $c_{\text {tot }}$ concentrations.
\end{abstract}

\section{Keywords}

Br-atom containing species; redox transitions; $\mathrm{pH}$, potential and concentration effects; thermodynamic equilibrium; redox charge of solution

* Corresponding authors: mikepetrovm@gmail.com (M. M. Petrov), vitkuzn1@ mail.ru (V. V. Kuznetsov), mivo2010@yandex.com (M. A. Vorotyntsev) 


\section{Introduction}

Anion electroreduction processes were thoroughly studied by A. N. Frumkin and associates in view of a strong influence of the electrical double layer structure on this reactions' rate [1-4]. Recently one of the processes of this type, bromate anion $\left(\mathrm{BrO}_{3}^{-}\right)$electroreduction, has drawn again attention in relation to prospects of its use as a cathodic process inside redox flow batteries (RFB) [5-8] of very high charge and energy density [9-11]. In view of the non-electroactivity of the bromate anion within the range of relatively low overvoltages this reaction can only pass via an indirect mechanism combining electrochemical and chemical steps. Theoretical analysis [12] showed that this reaction in strongly acidic solution might take place owing to a redox-mediator cycle composed of a (quasi)reversible transformation on the electrode surface:

$\mathrm{Br}_{2}+2 \mathrm{e}^{-} \rightleftarrows 2 \mathrm{Br}^{-}$

and the rapid comproportionation step inside the solution phase:

$\mathrm{BrO}_{3}^{-}+5 \mathrm{Br}^{-}+6 \mathrm{H}^{+} \rightarrow 3 \mathrm{Br}_{2}+3 \mathrm{H}_{2} \mathrm{O}$

Its peculiar feature is the autocatalytic character of this (EC") mechanism: each passage of the cycle leads to increase of the total number of $\mathrm{Br}_{2}$ and $\mathrm{Br}^{-}$species inside the diffusion layer of solution owing to the $\mathrm{BrO}_{3}{ }^{-}$transformation. Therefore, the cathodic current passage results in accumulation of the $\mathrm{Br}_{2}$ and $\mathrm{Br}^{-}$species near the electrode surface, which in its turn means enormous values of the current which may pass for high bromate and proton concentrations in the bulk solution, even at a very low concentration of the catalytic species, $\mathrm{Br}_{2}$, far from the electrode surface.

These theoretical predictions on the ability of the redox cycle based on reactions (1a) and (2a) to provide very high discharge current densities were confirmed experimentally for the RDE [13] and microelectrode [14] configurations as well as for the hydrogen-bromate discharge cell [15] The next requirement for applications of bromates in flow batteries is to ensure the backward transformation of the discharge product, bromide solution, into the starting oxidant, bromate, preferably via electrolysis. Experimental examples of the $\mathrm{Br}^{-}$electrooxidation leading to formation of $\mathrm{BrO}_{3}^{-}$have been described in literature [16-19]. However, values of controlling parameters of the electrolysis process were taken on the basis of simplified models which only took into account equilibria between principal Br-containing species. For their substantiated choice, especially for higher bromide and bromate concentrations one has to analyze the evolution of the solution in the course of its electrolysis. Our study represents an approach to this aim.

One has to take into account specific features of Br-containing systems in their intermediate oxidation degrees (between -1 for $\mathrm{Br}^{-}$and +5 for $\mathrm{BrO}_{3}{ }^{-}$). Because of the existence of such 
numerous Br-containing forms the oxidative electrolysis does not pass simply as series of successive transformations of $\mathrm{Br}^{-}$into $\mathrm{Br}_{2}$, then $\mathrm{Br}_{2}$ into $\mathrm{HBrO} / \mathrm{BrO}^{-}$and finally $\mathrm{HBrO} / \mathrm{BrO}^{-}$into $\mathrm{BrO}_{3}{ }^{-}$. On the contrary, various $\mathrm{Br}$-containing species of intermediate oxidation degrees coexist at the same time moment.

Bright chemistry following the dissolution of a single substance, molecular bromine, in pure water was illustrated by Michalowski [20]. Owing to the disproportionation stage, i.e. the reaction of solute $\mathrm{Br}_{2}$ molecules with water, Br-containing species of the $+1\left(\mathrm{HBrO}\right.$ and $\left.\mathrm{BrO}^{-}\right)$ and $-1\left(\mathrm{Br}^{-}\right)$oxidation degrees are generated which in their turn can give species of both +5 $\left(\mathrm{HBrO}_{3}\right.$ and $\left.\mathrm{BrO}_{3}^{-}\right)$and intermediate (for $\mathrm{Br}_{3}^{-}$ion) degrees. These reactions are accompanied by both proton equilibria (so that $\mathrm{pH}$ is shifted away from its initial value for pure water equal to 7 to lower values) and formation of redox couples (establishing a value of the equilibrium potential, $E$, which may be recorded by indicator electrode).

All these characteristics of the aqueous bromine solution at equilibrium, i.e. concentrations of all Br-containing compounds, $\mathrm{pH}$ and $E$, vary as functions of the amount of externally added bromine molecules. These dependences were calculated in Ref. [20] with the use of known thermodynamic constants of various chemical steps and redox half-reactions as well as balance relations for $\mathrm{Br}$ as element, ionic charges and bromine electrons.

In further publications these transformations between various $\mathrm{Br}$-containing solute species under equilibrium conditions were described for various titration processes, e.g. stepwise addition of aqueous $\mathrm{NaOH}$ solution into aqueous solution of $\mathrm{Br}_{2}$ or $\mathrm{HBrO}$ [21-24]. The above set of various Br-containing species was generated prior to titration while fractions of these species in mixed solutions were changing depending on the volume of added $\mathrm{NaOH}$ solution, $V$. Another series of titration processes was devoted to various combinations of two Br-containing solutions of different oxidation states, e.g. those of $\mathrm{NaBr}$ (with or without $\mathrm{H}_{2} \mathrm{SO}_{4}$ ) and $\mathrm{Br}_{2}$ or $\mathrm{KBrO}_{3}$ or $\mathrm{NaBrO}$ as well as those of $\mathrm{NaBr}+\mathrm{Br}_{2}$ or $\mathrm{NaBrO}$ (with or without $\mathrm{H}_{2} \mathrm{SO}_{4}$ ) and $\mathrm{KBrO}_{3}$, etc. [24,25]. At last the titration process was also considered for case where a different redox-active element (besides $\mathrm{Br}$ ) was involved, e.g. combinations of $\mathrm{NaBr}$ and $\mathrm{Cl}_{2}, \mathrm{Cl}_{2}$ and $\mathrm{KBrO}_{3}, \mathrm{NaBr}+$ $\mathrm{Cl}_{2}$ and $\mathrm{KBrO}_{3}[25]$ as well as $\mathrm{NaBr}+\mathrm{H}_{2} \mathrm{SO}_{4}$ and $\mathrm{Ce}\left(\mathrm{SO}_{4}\right)_{2} \cdot 4 \mathrm{H}_{2} \mathrm{O}[26]$.

Calculation of characteristics of both the pure titrand and mixed solutions (their compositions, $\mathrm{pH}, E$ ) as functions of $V$ (or of the ratio of $V$ and of the volume of the titrand solution) was based on the Generalized Approach to Electrolytic Systems (GATES) including Generalized Electron Balance (GEB) [20,22,25,27]. For systems where $\mathrm{Br}$ was the only redox-active element the set of equations determining the solution composition (in parallel with its $\mathrm{pH}$ and $E$ ) was composed of thermodynamic relations (Nernst equations for various half-reactions and expressions for 
equilibrium constants of chemical steps), material balances, i.e. conservation law for the total number of atoms of each chemical element $(\mathrm{Br}, \mathrm{H}, \mathrm{O}$, etc.) in all species of the system (called "Concentration Balance" or "Elemental Balance" [20,22,25,27]), electroneutrality condition for the solution (called "Charge Balance" [20,22,25,27]) and GEB which represent the balance relation for the total number of electrons at all $\mathrm{Br}$ atoms in all oxidation states.

All these transformations after bromine dissolution or after formation of a mixed solution in the course of titration took place inside the solution phase with no supply of external electricity by electrochemical means. Therefore, the total redox charge, $Q$ (this term is defined strictly in the next section) of the pure titrand or mixed solution in its equilibrium state remains equal to the one of its constituents, i.e. of the components used for its preparation. For example, the total redox charge of the $\mathrm{Br}_{2}$ solution in water, or of any mixed solution in the course of $\mathrm{Br}_{2}$ titration by $\mathrm{NaOH}$, is always equal to zero. Similarly, it is equal to $-F N_{\mathrm{Br}-}$ for titration of $\mathrm{NaBr}$ by $\mathrm{NaOH}$ or by $\mathrm{Br}_{2}$ or to $F\left(-N_{\mathrm{Br}-}+5 N_{\mathrm{BrO} 3}\right)$ for titration of $\mathrm{NaBr}$ by $\mathrm{KBrO}_{3}\left(N_{\mathrm{Br}-}\right.$, number of $\mathrm{Br}^{-}$moles in titrand; $N_{\mathrm{BrO}-}$, number of $\mathrm{BrO}_{3}{ }^{-}$moles in added $\mathrm{KBrO}_{3}$ solution dependent on its volume, $V$ ).

Electrochemical tools represent an alternative way to modify the solution composition by means of its electrolysis (see e.g. book [28]), i.e. via passage of a significant electric charge, $Q_{\text {elchem, }}$ through the circuit which is spent for transformations of electroactive species at the electrode/solution boundary. For research goals (contrary to industrial electrolyses) this process is typically carried out in three-electrode cells where the anodic and cathodic compartments are separated by ion conducting membrane.

Electrolysis process is frequently performed in the presence of excess of background electrolyte (also called "excess electrolyte" or "supporting electrolyte" [28]); words "background"/"supporting" and "excess" imply that the products of the ionic dissociation of the electrolyte in solution do not participate in electrochemical transformations at the electrode/solution boundary and that the electrolyte is well dissociated and its concentration is much higher than those of electroactive species, respectively. Owing to its addition one can not only diminish ohmic losses and make the current distribution over the electrode surface more uniform [28] but also reduce the rate of exchange by electroactive species across the membrane in the course of electrolysis.

If the transformation of electroactive species at the electrode/solution boundary is accompanied by generation or consumption of protons $\left(\mathrm{H}^{+}\right)$or/and $\mathrm{OH}^{-}$ions the solution's $\mathrm{pH}$ can change strongly in the course of electrolysis, thus resulting frequently to modification of the mechanism of the proceeding electrochemical reactions. The conventional tool to avoid this problem is to use a pH buffer ("(well) buffered solution" [28]). It means that the concentrations of its 
constituents are much higher than those of electroactive species. Then, the solution's $\mathrm{pH}$ remains practically constant (and known), despite the passage of $\mathrm{pH}$-related electrochemical and chemical processes. Moreover, ionic species of the $\mathrm{pH}$ buffer can often play simultaneously the role of the background electrolyte [28].

If the electrolysis of the $\mathrm{Br}$-containing solution is carried out under conditions where the electrochemical charge, $Q_{\text {elchem, }}$ passed by a time moment of the electrolysis, $t$, is fully spent for the change of the oxidation degrees of $\mathrm{Br}$ atoms inside the system the measured value of $Q_{\text {elchem }}$ provides a direct information on the difference between the total redox charges of the system prior to electrolysis, $Q_{\mathrm{ini}}$, and at the chosen time moment, $Q$ (see its definition in section 2.1 below):

$Q_{\text {elchem }}=Q-Q_{\text {ini }}$

Since the initial value of the total redox charge, $Q_{\text {ini }}$, can be calculated (see section 2.1 below) on the basis of the procedure of the starting solution preparation Eq (1) enables one to monitor the variation of the total redox charge of the system as a function of time, $t$.

Since the duration of electrolysis is typically relatively long (from tens of minutes up to many hours or even days) one can interrupt temporarily the process (by breaking the passing current) in order to measure (after termination of the relaxation process) the equilibrium potential of the working electrode in contact with the electrolyzed solution, $E$, with respect to reference electrode. An alternative method to measure this potential, $E$ (with respect to the same reference electrode) is to use an additional indicator electrode immersed into the electrolyzed solution so that the same electroactive species would react at its surface. Thus, one can record the evolution of the electrode potential, $E$, as a function of time, $t$.

One may choose any of these electric variables, the total redox charge of the system at a moment, $Q$, or its electrode potential, $E$, as a known external parameter (formally, it means to consider the system after passage of a certain electrochemical charge, $Q_{\text {elchem, }}$ Eq (1), or after reaching a certain equilibrium potential, $E$ ). Then, the second electric characteristic (as well as the solution composition) will be determined by the chosen electric parameter and other imposed external parameters, e.g. the total amount of $\mathrm{Br}$ atoms inside the system, $N_{\text {tщe }}=c_{\text {tot }} V^{\text {sol }}$, and the solution's $\mathrm{pH}$.

The goal of this study has been to propose a procedure for calculation of these dependences in the course of electrolyses of Br-containing systems. Potential, $E, \mathrm{pH}$ and $c_{\text {tot }}$ will be used as known external parameters of the system.

The approach developed in Refs [20,22,25,27] cannot be applied because of several reasons: 
1) Equation for the electron balance (GEB) used in the above papers cannot be applied since it does not include the effect of the electrochemical charge. It is why a different relation based on the redox charge balance has been derived in this study (see the next section). It should be used as one of the equations for determination of the equilibrium solution composition and the potential, $E$, if the total redox charge, $Q$, is used as a known parameter. On the contrary, if the electrode potential, $E$, is used as such a parameter, then the redox charge balance enables one to calculate the equilibrium total redox charge, $Q$, as a function of $E, \mathrm{pH}$ and $c_{\text {tot }}$ (see below).

2) Owing to the presence of excessive background electrolyte the electroneutrality condition for solute ions ("charge balance") is no longer needed as one of the constituent equations since the change of the ionic charge density of Br-containing species due to the change of the total redox charge, Eq (1), is dominantly compensated by these background ions: owing to the continuity condition for the current any passed electrochemical charge in Eq (1) is compensated by the passage of the equal charge of background ions across the membrane while these charges are negligibly small compared to the total ionic charge of the background electrolyte.

3) In the presence of the $\mathrm{pH}$ buffer of a sufficiently large capacity the $\mathrm{pH}$ value of the solution is determined by the properties of this buffer, i.e. it is fixed and known. Owing to points 2 and 3; the elemental balances for $\mathrm{H}, \mathrm{O}$ and other non-electroactive atoms as well as the waterdissociation equilibrium relation are no longer needed, either.

As a result, the equilibrium state of the Br-containing system is determined (for fixed and known values of $E, \mathrm{pH}$ and $c_{\mathrm{tot}}$ ) by the set of algebraic equations consisting of thermodynamic laws for the equilibrium state of electrochemical and chemical reactions as well as the balance relation for $\mathrm{Br}$ atoms in all oxidation degrees inside the system, see the next section.

Such studies of electrochemical properties of the Br-containing system represent a vivid interest in relation to redox flow batteries, a rapidly developing type of electrochemical energy sources, based on bromine, $\mathrm{Br}_{2}$ (more precisely, on tribromide, $\mathrm{Br}_{3}{ }^{-}$, in view of the limited solubility of $\mathrm{Br}_{2}$ in water, see below) or bromate, $\mathrm{BrO}_{3}{ }^{-}$, ions as cathodic reagents [7,10,15,29-33]. The information on the composition of such solutions as a function of the potential or of their total redox charge is of importance for description of processes both in their discharge devices and also in their regeneration reactors where the products of the discharge process are to be transformed back to the corresponding reagents electrochemically. Another applied area where the knowledge of the electrochemically-driven evolution of the composition of the Br-containing solution is needed is the disinfection process of drinking water by electrolysis for which it is of importance to predict conditions where hazardous $\mathrm{Br}$-containing compounds can be generated so that their formation may be avoided [17,18,34]. 


\section{Theoretical analysis}

\subsection{Definitions and balance relations}

Analogously to Refs [20,21-25] we take into account Br-containing solute species of oxidation degrees from -1 to +5 , see species from $i=1$ to $i=7$ in Table 1 . Transitions into the highest oxidation state, +7 , are not considered because the standard potential of its formation (over 1.8 V) belongs to the area where it is difficult to avoid electrochemical processes with participation of other solution components.

Non-dissociated forms of strong acids, $\mathrm{HBr}, \mathrm{HBr}_{3}, \mathrm{HBr}_{5}, \mathrm{HBrO}_{3}$, are not considered since their concentrations with respect to the corresponding ion are very small, at least within the whole range: $\mathrm{pH}>0$, e.g. signal of $\mathrm{HBrO}_{3}$ is not visible in $\mathrm{Raman}$ spectra of $3 \mathrm{M} \mathrm{HBrO}_{3}$ [35]. Because of the relatively low solubility of $\mathrm{Br}_{2}$ in water one has to take into account liquid bromine, $\mathrm{Br}_{2}{ }^{\text {liq }}$ $(\mathrm{i}=8)$ which is in equilibrium with solute $\mathrm{Br}_{2}$ at its saturated concentration: $\left[\mathrm{Br}_{2}\right.$,sat $]=0.185 \mathrm{M}$ [36]. Another physical process is evaporation of solute bromine into the gas phase $\left(\mathrm{Br}_{2}{ }^{\text {vap }, \mathrm{i}=9)}\right.$ over its solution.

Table 1 also contains a row of the numbers of $\mathrm{Br}$ atoms in each species $\left(n_{\mathrm{i}}\right)$.

Table 1.

\begin{tabular}{|c|c|c|c|c|c|c|c|c|c|}
\hline $\mathrm{i}$ & 1 & 2 & 3 & 4 & 5 & 6 & 7 & 8 & 9 \\
\hline & $\mathrm{Br}^{-}$ & $\mathrm{Br}_{3}^{-}$ & $\mathrm{Br}_{5}^{-}$ & $\mathrm{Br}_{2}$ & $\mathrm{HBrO}$ & $\mathrm{BrO}^{-}$ & $\mathrm{BrO}_{3}^{-}$ & $\mathrm{Br}_{2}^{\text {liq }}$ & $\mathrm{Br}_{2}^{\text {vap }}$ \\
\hline$n_{\mathrm{i}}$ & 1 & 3 & 5 & 2 & 1 & 1 & 1 & 2 & 2 \\
\hline$x_{\mathrm{i}}$ & -1 & -1 & -1 & 0 & +1 & +1 & +5 & 0 & 0 \\
\hline
\end{tabular}

Another useful parameter of each species is its total oxidation number of $\mathrm{Br}$ atom(s) inside the species, $x_{\mathrm{i}}$. It is defined with the use of the corresponding electrochemical reaction where one species, $\mathrm{i}$, is transformed into solute bromine, neutral $\mathrm{Br}_{2}$ molecule $(\mathrm{i}=4)$, for which the total oxidation number is taken as zero: $x_{4}=0$, e.g.

$\mathrm{Br}^{-}-\mathrm{e}^{-}=1 / 2 \mathrm{Br}_{2}, \mathrm{Br}_{3}^{-}-\mathrm{e}^{-}=3 / 2 \mathrm{Br}_{2}, \mathrm{BrO}_{3}^{-}+6 \mathrm{H}^{+}+5 \mathrm{e}^{-}=1 / 2 \mathrm{Br}_{2}+3 \mathrm{H}_{2} \mathrm{O}$

i.e. one should withdraw 1 electron from $1 \mathrm{Br}^{-}$species of type $1(\mathrm{i}=1)$ so that $x_{1}=-1$, or withdraw 1 electron from $1 \mathrm{Br}_{3}{ }^{-}$species of type $2(\mathrm{i}=2)$ so that $x_{2}=-1$, or add 5 electrons to 1 $\mathrm{BrO}_{3}{ }^{-}$species of type $7(\mathrm{i}=7)$ so that $x_{7}=-1$. For species containing only one $\mathrm{Br}$ atom the value of thus defined parameter, $x_{\mathrm{i}}$, is equal to its conventional oxidation degree (oxidation number) while it avoids fractional numbers for species including several $\mathrm{Br}$ atoms, see Table 1.

If the Br-containing species do not leave the working-electrode compartment in the course of electrolysis, then the total number of moles of $\mathrm{Br}$ atoms in all Br-containing components of the system (including the species which are not dissolved in solution), $N_{\text {tot }}$, does not change in time 
so that it may be calculated of the basis of the solution preparation procedure. This value is included into the balance equation for $\mathrm{Br}$ atoms:

$N_{\mathrm{tot}}=\sum n_{\mathrm{i}} N_{\mathrm{i}}$

where the summation is carried out over all Br-containing components in Table $1, N_{\mathrm{i}}$ is the number of moles of Br-containing species of type $\mathrm{i}$ at a time moment, $t$, in the course of electrolysis, numbers $n_{\mathrm{i}}$ are given in Table 1 .

The total redox charge of the Br-containing system (where all other elements are nonelectroactive, i.e. they do not change their oxidation degrees) is defined by the formula:

$Q=F \sum x_{\mathrm{i}} N_{\mathrm{i}}$

where total oxidation numbers, $x_{\mathrm{i}}$, for all species may be found in Table 1 .

Average oxidation degree, $x$, of $\mathrm{Br}$ atoms in this state of the system characterizes the average redox charge per one $\mathrm{Br}$ atom (in dimensionless units):

$x=Q / F N_{\text {tot }}=\sum x_{\mathrm{i}} N_{\mathrm{i}} / \sum n_{\mathrm{i}} N_{\mathrm{i}}$

If the system in its initial state (prior to electrolysis) is prepared by dissolution of $N_{\text {ini }}$ moles of a substance where each molecule contains $n_{\text {ini }} \mathrm{Br}$ atoms and where the total oxidation number is equal to $x_{\text {ini }}$, then $N_{\text {tot }}=n_{\text {ini }} N_{\text {ini }}, Q_{\text {ini }}=F x_{\text {ini }} N_{\text {ini }}$. For example, $n_{\text {ini }}=1, x_{\text {ini }}=-1$ for the initial $\mathrm{NaBr}$ solution, $n_{\text {ini }}=2, x_{\text {ini }}=0$ for the initial $\mathrm{Br}_{2}$ solution while $n_{\text {ini }}=1, x_{\text {ini }}=+5$ for the initial $\mathrm{NaBrO}_{3}$ solution. If the initial solution is prepared by dissolution of two Br-containing substances the values of $N_{\text {tot }}$ and $Q_{\text {ini }}$ are given by the sum of their contributions. Presence of other solute species which are non-electroactive (i.e. do not participate in redox reactions at the electrode or inside the solution) does not affect these relations.

The knowledge of values of $Q_{\text {ini }}$ and of experimentally measured electrolysis charge, $Q_{\text {elchem, by }}$ some time moment, $t$, enables one to calculate the total redox charge of the system for this moment, $Q=Q_{\text {ini }}+Q_{\text {elchem }}, \mathrm{Eq}(1)$.

Thermodynamic relations are formulated (see below) in terms of concentrations of Br-containing species in solution. The corresponding reactions take place either between $\mathrm{Br}$-containing species in aqueous solution or between $\mathrm{Br}_{2}$ molecules inside and outside this solution. Volume of the aqueous solution, $V^{\text {sol }}$, that can generally vary in the course of electrolysis is taken at the corresponding time moment, $t$.

Then, the balance reaction for $\mathrm{Br}$ atoms, $\mathrm{Eq}(3)$, may rewritten in the form:

$c_{\mathrm{tot}}=\sum n_{\mathrm{i}} c_{\mathrm{i}}$, 
where $c_{\text {tot }}=N_{\text {tot }} / V^{\mathrm{sol}}, c_{\mathrm{i}}=N_{\mathrm{i}} / V^{\mathrm{sol}}$ for all species in Table $1(\mathrm{i}=1, \ldots 9)$. For $\mathrm{i}=1, \ldots 7$ thus defined quantities, $c_{\mathrm{i}}$, are equal to the concentrations of the corresponding solute species inside aqueous solution. On the contrary, for $\mathrm{i}=8$ and $\mathrm{i}=9$ the corresponding $\mathrm{Br}_{2}$ molecules are located in a different phase (as liquid bromine or inside gas phase over the solution) so that the values of $c 8$ and $c_{9}$ as well as of "the total concentration of $\mathrm{Br}$ atoms", $c_{\text {tot }}$, represent formally introduced effective concentrations. Nevertheless, their use is convenient since it allows one to estimate immediately which fraction of the total number of $\mathrm{Br}$ atoms of the system is present in these forms.

Eq (6) may be written down in the explicit form:

$\left[\mathrm{Br}^{-}\right]+3\left[\mathrm{Br}_{3}^{-}\right]+5\left[\mathrm{Br}_{5}^{-}\right]+2\left[\mathrm{Br}_{2}\right]+[\mathrm{HBrO}]+\left[\mathrm{BrO}^{-}\right]+\left[\mathrm{BrO}_{3}^{-}\right]+$

$+2\left[\mathrm{Br}_{2}{ }^{\mathrm{vap}}\right]_{\mathrm{sol}}+2\left[\mathrm{Br}_{2}{ }^{\mathrm{liq}}\right]_{\mathrm{sol}}=c_{\mathrm{tot}}$

$\left[\mathrm{Br}_{2}{ }^{\text {liq }}\right]_{\text {sol }}=N\left(\mathrm{Br}_{2}{ }^{\text {liq }}\right) / V^{\text {sol }}, \quad\left[\mathrm{Br}_{2}{ }^{\mathrm{vap}}\right]_{\text {sol }}=N\left(\mathrm{Br}_{2}{ }^{\text {vap }}\right) / V^{\text {sol }}=\left[\mathrm{Br}_{2}{ }^{\mathrm{vap}}\right] V^{\mathrm{gas}} / V^{\text {sol }}$,

where $\left[\mathrm{Br}_{2}{ }^{\mathrm{vap}}\right]$ is the concentration of $\mathrm{Br}_{2}$ in the gas phase.

The total redox charge, $Q$, may also be expressed via the above defined concentrations, $c_{\mathrm{i}}$ :

$Q=F V^{\mathrm{sol}} c_{\mathrm{Q}}$, where $c_{\mathrm{Q}}=\sum x_{\mathrm{i}} c_{\mathrm{i}}$

The explicit form of this redox balance relation is given by Eq (10):

$c_{\mathrm{Q}}=-\left[\mathrm{Br}^{-}\right]-\left[\mathrm{Br}_{3}^{-}\right]-\left[\mathrm{Br}_{5}^{-}\right]+[\mathrm{HBrO}]+\left[\mathrm{BrO}^{-}\right]+5\left[\mathrm{BrO}_{3}^{-}\right]$

The average oxidation degree defined by $\mathrm{Eq}(5)$ is directly related to this effective concentration of the redox charge of $\mathrm{Br}$ atoms, $c_{\mathrm{Q}}$ :

$x=c_{\mathrm{Q}} / c_{\mathrm{tot}}$

By definition, the value of $x$ is equal to 0 for the solution obtained by dissolution of pure bromine, $\mathrm{Br}_{2}$, in water while according to Eqs (7) and (11) it varies from -1 for pure $\mathrm{Br}^{-}$solution to +5 for pure $\mathrm{BrO}_{3}{ }^{-}$one.

\subsection{Thermodynamic relations}

Under equilibrium conditions the concentrations of all components satisfy thermodynamic relations for all possible transformations inside the bromine system where one should retain a set of mutually independent ones, their number being identical to the number of solute components minus 1 .

These relations for electrochemical and chemical reactions taking place inside this system contain activities of participating species. To get a closed set of equations for determination of the system's composition (values of $c_{\mathrm{i}}$ ) one should rewrite them via concentrations. 
For example, the Nernst equation for the electrochemical reaction:

$\mathrm{BrO}_{3}^{-}+6 \mathrm{H}^{+}+6 \mathrm{e}^{-}=\mathrm{Br}^{-}+3 \mathrm{H}_{2} \mathrm{O}$

has the form:

$6 A\left(E-E_{1}{ }^{\circ}\right)=\log \left\{\mathrm{BrO}_{3}{ }^{-}\right\}+6 \log \left\{\mathrm{H}^{+}\right\}-\log \left\{\mathrm{Br}^{-}\right\}$,

$A=F /(R T \log 10)=16.92 \mathrm{~V}^{-1}, \quad E_{1}{ }^{0}=1.409 \mathrm{~V}[37]$

Here and below, all potentials are given vs. normal (standard) hydrogen electrode (SHE). The relation can be rewritten with the use of the definition of $\mathrm{pH}$ as well as the relation between the activity, molar concentration and activity coefficient of a species of type $\mathrm{i}, a_{\mathrm{i}}=c_{\mathrm{i}} f_{\mathrm{i}}$ :

$6 A\left(E-E_{1}{ }^{\circ}\right)+6 \mathrm{pH}=\log \left[\mathrm{BrO}_{3}^{-}\right]-\log \left[\mathrm{Br}^{-}\right]+\log f\left(\mathrm{BrO}_{3}^{-}\right) / f\left(\mathrm{Br}^{-}\right)$,

so that

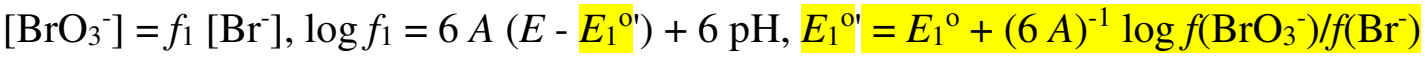

This form of the Nernst equation written for the concentrations of Br-containing species participating in reaction (12) contains the formal potential, $E_{1}{ }^{{ }^{\prime}}$, which is shifted compared to its standard potential, $E_{1}{ }^{\circ}$, due to the activity coefficient term. In the presence of excess of background electrolyte the values of the activity coefficients are determined by this electrolyte so that they are not affected by passage of redox reactions between Br-containing species, i.e. the value of $E_{1}{ }^{0 \prime}$ is constant the electrolysis process.

Similar transformations enable one to derive Nernst equations in terms of concentrations for two other electrochemical transformations:

$\mathrm{HBrO}+\mathrm{H}^{+}+2 \mathrm{e}^{-}=\mathrm{Br}^{-}+\mathrm{H}_{2} \mathrm{O},[\mathrm{HBrO}]=f_{2}\left[\mathrm{Br}^{-}\right], \log f_{2}=2 A\left(E-E_{2}{ }^{\mathrm{o}}\right)+\mathrm{pH}$

$\mathrm{Br}_{2}+2 \mathrm{e}^{-}=2 \mathrm{Br}^{-},\left[\mathrm{Br}_{2}\right]=f_{3}\left[\mathrm{Br}^{-}\right]^{2}, \log f_{3}=2 A\left(E-E_{3}{ }^{{ }^{\prime}}\right)$

where $E_{2}{ }^{\mathrm{o}}=1.341 \mathrm{~V}$ and $E_{3}{ }^{\mathrm{o}}=1.0874 \mathrm{~V}$ [37], $E_{2}{ }^{\mathrm{o}}=E_{2}{ }^{\mathrm{o}}+(2 \mathrm{~A})^{-1} \log \left[f(\mathrm{HBrO}) / f(\mathrm{Br}-)\left\{\mathrm{H}_{2} \mathrm{O}\right\}\right]$, $E_{3}{ }^{\mathrm{o}}=E_{3}{ }^{\mathrm{o}}+(2 \mathrm{~A})^{-1} \log \left[f\left(\mathrm{Br}_{2}\right) / f^{2}(\mathrm{Br}-)\right]$.

There are also chemical reactions between the solute components giving rise to tribromide and pentabromide anions where the equilibrium conditions contain activities of participating species:

$$
\begin{aligned}
& \mathrm{Br}_{3}{ }^{-}=\mathrm{Br}^{-}+\mathrm{Br}_{2},\left\{\mathrm{Br}_{3}^{-}\right\}=\mathrm{K}_{4}\left\{\mathrm{Br}^{-}\right\}\left\{\mathrm{Br}_{2}\right\}, \\
& \mathrm{Br}_{5}{ }^{-}=\mathrm{Br}_{3}^{-}+\mathrm{Br}_{2},\left\{\mathrm{Br}_{5}^{-}\right\}=\mathrm{K}_{5}\left\{\mathrm{Br}_{3}^{-}\right\}\left\{\mathrm{Br}_{2}\right\}=\mathrm{K}_{5} \mathrm{~K}_{4}\left\{\mathrm{Br}^{-}\right\}\left\{\mathrm{Br}_{2}\right\}^{2} .
\end{aligned}
$$

These chemical equilibria can be represented by equivalent electrochemical ones with the use of Eq (17) rewritten again in terms of concentrations of reagents:

$\mathrm{Br}_{3}^{-}+2 \mathrm{e}^{-}=3 \mathrm{Br}^{-},\left[\mathrm{Br}_{3}^{-}\right]=f_{4}\left[\mathrm{Br}^{-}\right]^{3}$, 
$\log f_{4}=2 A\left(E-E_{4}{ }^{{ }^{\prime}}\right), E_{4}{ }^{{ }^{\prime \prime}}=E_{4}{ }^{\mathrm{o}}+(2 \mathrm{~A})^{-1} \log f\left(\mathrm{Br}_{3}{ }^{-}\right) / f^{3}\left(\mathrm{Br}^{-}\right)$

$\mathrm{Br}_{5}^{-}+4 \mathrm{e}^{-}=5 \mathrm{Br}^{-},\left[\mathrm{Br}_{5}^{-}\right]=f_{5}\left[\mathrm{Br}^{-}\right]^{5}$,

$\log f_{5}=4 A\left(E-E_{5}{ }^{\mathrm{o}^{\prime}}\right), E_{5}{ }^{\mathrm{o}^{\prime}}=E_{5}{ }^{\mathrm{o}}+(2 \mathrm{~A})^{-1} \log f\left(\mathrm{Br}_{5}^{-}\right) / f^{5}\left(\mathrm{Br}^{-}\right)$

where $2 A\left(E_{3}{ }^{o}-E_{4}{ }^{o}\right)=\log K_{4}, E_{4}{ }^{o}=1.0503 \mathrm{~V}$ [37], $\log K_{4}=1.25, K_{4}=17.9,4 A\left(E_{3}{ }^{\mathrm{o}}-E_{5}{ }^{\mathrm{o}}\right)=$ $\log \left(K_{5} K_{4}\right), K_{5}=1.54[36], E_{5}{ }^{\circ}=1.066 \mathrm{~V}$.

There are also protonation/deprotonation equilibria between anions and their non-dissociated acids. Most of these acids are very strong so that we neglect the presence of their non-dissociated forms. On the contrary, hypobromous acid, $\mathrm{HBrO}$, is relatively weak so that its dissociation equilibrium is shifted towards the acid for most $\mathrm{pH}$ :

$\mathrm{HBrO}=\mathrm{BrO}^{-}+\mathrm{H}^{+},[\mathrm{HBrO}]=K_{\mathrm{H}^{\prime}}\left[\mathrm{BrO}^{-}\right]$,

$K_{\mathrm{H}^{\prime}}=K_{\mathrm{H}} f\left(\mathrm{BrO}^{-}\right) / f(\mathrm{HBrO}), \log K_{\mathrm{H}}=8.6-\mathrm{pH}[20]$.

At last, one has to take into account two physical equilibria, namely: 1) formation of the phase of liquid bromine, $\mathrm{Br}_{2}{ }^{\text {liq }}$, if the amount of bromine exceeds its saturation level, $\mathrm{Eq}(23) ; 2$ ) evaporation of bromine into the gas phase $\left(\mathrm{Br}_{2}{ }^{\text {vap }}\right)$ over its solution, $\mathrm{Eq}(24)$ :

$\mathrm{Br}_{2}{ }^{\text {liq }}=\mathrm{Br}_{2}$,sat, where $\left[\mathrm{Br}_{2}\right.$,sat $]=0.185 \mathrm{M}[36]$,

$\mathrm{Br}_{2}{ }^{\text {vap }}=\mathrm{Br}_{2}$

Concentration of bromine in its saturated aqueous solution, $\left[\mathrm{Br}_{2}\right.$,sat], that is in equilibrium with the $\mathrm{Br}_{2}$ liquid phase is related to the standard potentials of the electrochemical equilibria:

$\mathrm{Br}_{2}{ }^{\text {liq }}+2 \mathrm{e}^{-}=\mathrm{Br}_{2, \text { sat }}+2 \mathrm{e}^{-}=2 \mathrm{Br}^{-}$,

$\left[\mathrm{Br}^{-}\right]^{-2}=1 / f_{6}=\left[\mathrm{Br}_{2}\right.$, sat $] / f_{3}, \log f_{6}=2 A\left(E-E_{6}{ }^{\circ}\right), E_{6}{ }^{{ }^{\prime \prime}}=E_{6}{ }^{\circ}-\mathrm{A}^{-1} \log f\left(\mathrm{Br}^{-}\right)$

so that $\log \left[\mathrm{Br}_{2}\right.$,sat $]=\log \left(f_{3} / f_{6}\right)=2 A\left(E_{3}{ }^{{ }^{\prime \prime}}-E_{6}{ }^{{ }^{\prime}}\right)=2 A\left[E_{3}{ }^{\mathrm{o}}-E_{6}{ }^{\mathrm{o}}\right]+\log f\left(\mathrm{Br}_{2}\right)$. The above values of $\left[\mathrm{Br}_{2}\right.$,sat $]$ and $E_{3}{ }^{\mathrm{o}}$ give $E_{6}{ }^{\mathrm{o}}=1.0657 \mathrm{~V}$ after neglect of the last term, $\log f\left(\mathrm{Br}_{2}\right)$, in good agreement with the literature value, $1.0652 \mathrm{~V}$ [37].

Total amount of bromine in the vapor state, $N\left(\mathrm{Br}_{2}{ }^{\text {vap }}\right)$, dependent on its molar concentration, $\left[\mathrm{Br}_{2}{ }^{\text {vap }}\right]$, and the gas volume over the solution, $V^{\text {gas }}$ (it is assumed that the cell containing the solution and the gas space is hermetic as a whole), is proportional to the activity of bromine in the solution:

$N\left(\mathrm{Br}_{2}{ }^{\text {vap }}\right)=\left[\mathrm{Br}_{2}{ }^{\text {vap }}\right] V^{\text {gas }},\left[\mathrm{Br}_{2}{ }^{\text {vap }}\right]=K_{\text {vap }}{ }^{\prime}\left[\mathrm{Br}_{2}\right], K_{\text {vap }}{ }^{\prime}=K_{\text {vap }} f\left(\mathrm{Br}_{2}\right)$

where the distribution constant, $K_{\text {vap }}$, is equal to $6.2 * 10^{-6}$ at room temperature [36]. 
As it has already been discussed above there are two choices of the electric variable: electrode potential, $E$, or total redox charge of the system, $Q$. The analysis below is carried out for the former variant. Alternatively, for the latter option the potential, E, inside thermodynamic relations is an unknown quantity. Then, one should add the redox balance relation for $Q, \mathrm{Eq}(9)$, into the set of equations discussed below so that its solution determines both the composition of the system and the potential, $E$.

If the potential, $E$, is known Eqs (15)-(17),(20)-(22),(26) represent 7 relations between 8 concentrations of Br-containing components: [ $\left.\mathrm{Br}^{-}\right],\left[\mathrm{BrO}_{3}^{-}\right],[\mathrm{HBrO}],\left[\mathrm{Br}_{2}\right],\left[\mathrm{Br}_{3}^{-}\right],\left[\mathrm{Br}_{5}^{-}\right],\left[\mathrm{BrO}^{-}\right]$, $N\left(\mathrm{Br}_{2}{ }^{\text {vap }}\right)$. If the liquid bromine phase is not formed, $N\left(\mathrm{Br}_{2}{ }^{\text {liq }}\right)=0$, then Eqs (7) and (8) provide the 8th relation between the same quantities. On the contrary, in the presence of the liquid bromine phase its amount represents an extra known quantity, $N\left(\mathrm{Br}_{2}{ }^{\text {liq }}\right)$, so that this set of equations is not closed.

Equilibrium concentrations of all components in Eq (7) as well as values of total redox charge, $Q$, Eq (10), and oxidation degree, $x$, Eq (11), depend on three parameters of the system: $c_{t o t}, \mathrm{pH}$ and $E$. Their values are considered as known. Potential, $E$, and $\mathrm{pH}$ can be measured directly by indicator electrode (scaled vs. proper reference electrode, e.g. SHE) and $\mathrm{pH}$-meter. Total amount of $\mathrm{Br}$ atoms inside the system, $N_{\text {tot }}$, is determined by experimental conditions, in particular frequently it does not change in the course of the procedure, e.g. of the electrolysis.

\subsection{Conditions of liquid bromine phase formation}

Liquid bromine phase exists under equilibrium conditions for certain combinations of the three parameters of the system, $E, \mathrm{pH}$ and $c_{\text {tot }}$, while it is absent for other combinations. These two regions are separated by a set of their critical values which form a two-dimensional (2D) surface inside the three-dimensional (3D) space of the system's parameters.

For each point of this surface the solute bromine concentration, $\left[\mathrm{Br}_{2}\right]$, is equal to its saturation concentration, $\left[\mathrm{Br}_{2}\right]_{\text {sat }}$, defined by $\mathrm{Eq}(25)$ while the liquid bromine phase is still absent. As a result, balance equation (7) takes the form:

$\left[\mathrm{Br}^{-}\right]^{*}+2\left[\mathrm{Br}_{2}\right]^{*}+3\left[\mathrm{Br}_{3}^{-}\right]^{*}+5\left[\mathrm{Br}_{5}^{-}\right]^{*}+[\mathrm{HBrO}]^{*}+\left[\mathrm{BrO}^{-}\right]^{*}+\left[\mathrm{BrO}_{3}{ }^{-}\right]^{*}+$

$+2\left[\mathrm{Br}_{2}^{\mathrm{vap}}\right]_{\mathrm{sol}} *=c_{\mathrm{tot}} *$

where the symbol, *, implies that these concentrations correspond to a critical state, solute bromine concentration, $\left[\mathrm{Br}_{2}\right]^{*}$, is always given by $\mathrm{Eq}(28)$ :

$\left[\mathrm{Br}_{2}\right]^{*}=\left[\mathrm{Br}_{2}\right.$, sat $]=0.185 \mathrm{M}$ 
Eqs (15)-(17),(20)-(22),(26) retain their validity if all concentrations in them are replaced by their critical values, $\left[\mathrm{Br}^{-}\right]^{*},\left[\mathrm{BrO}_{3}\right]^{*},[\mathrm{HBrO}]^{*},\left[\mathrm{Br}_{2}\right]^{*},\left[\mathrm{Br}_{3}^{-}\right]^{*},\left[\mathrm{Br}_{5}^{-}\right]^{*},\left[\mathrm{BrO}^{-}\right]^{*}$ and $N\left(\mathrm{Br}_{2}{ }^{\text {vap }}\right)^{*}$. Since the value of $\left[\mathrm{Br}_{2}\right]^{*}$ is known, Eq (28), one can find (for any known values of $E$ and $\mathrm{pH}$ ) $\left[\mathrm{Br}^{-}\right]^{*}$ from $\mathrm{Eq}(15)$, then values of all other critical concentrations as well as of the total concentration, $c_{\text {tot }}^{*}$, can be determined from these relations.

This value of $c_{\text {tot }} *$ separates two $c_{\text {tot }}$ subintervals: $c_{\text {tot }}<c_{\text {tot }} *$ where the liquid bromine phase is absent and $c_{\text {tot }}>c_{\text {tot }} *$ where the liquid bromine phase is present. As it is shown in further sections the procedures to calculate the distribution of the Br-atom containing components are quite different for these two cases.

Dependence of $c_{\text {tot }} *$ on the potential, $E$, for several $\mathrm{pH}$ values is illustrated in Fig. 1a. These graphs have the form of lines with a minimum, $\left(c_{\mathrm{tot}}{ }^{*}\right)_{\min }$, at a medium value of the potential, $E_{\min }$. Such a shape is the consequence of the composition of solution for sufficiently large negative or positive potentials. In the former case it is bromide anion, $\mathrm{Br}^{-}$, which becomes a predominant species while the solute bromine concentration, $\left[\mathrm{Br}_{2}\right]$, is exponentially low, according to $\mathrm{Eq}$ (17) via the $f_{3}$ factor. In the latter case it is bromate anion, $\mathrm{BrO}_{3}{ }^{-}$(or its acid, $\mathrm{HBrO}_{3}$ ) which becomes the principal component while the $\left[\mathrm{Br}_{2}\right]$ fraction is very small.
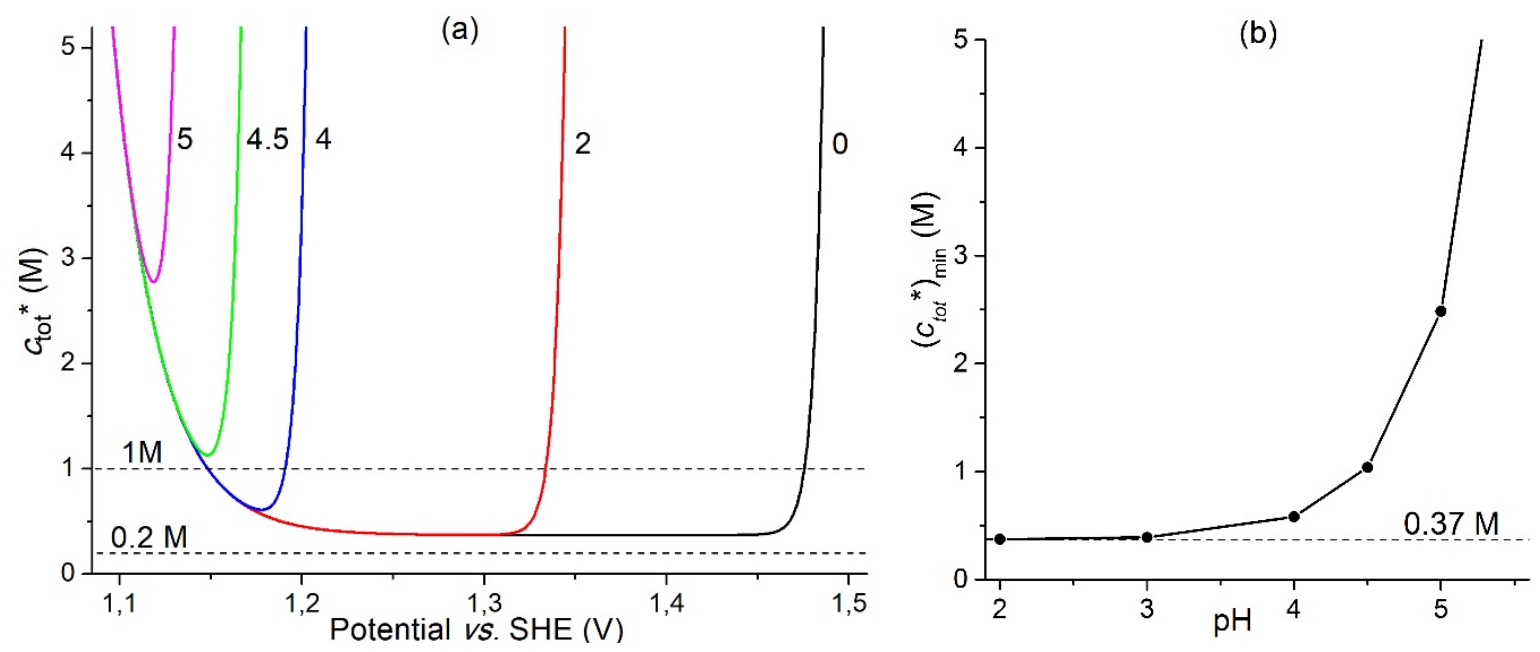

Fig. 1. (a) Dependence of critical total concentration, $c_{\text {tot }}{ }^{*}$, on potential, $E$, for several $\mathrm{pH}$ values (indicated at each graph).. Horizontal lines: $c_{\text {tot }}=0.2 \mathrm{M}$ or $c_{\text {tot }}=1 \mathrm{M}$ (b) Dependence of the minimal value of critical total concentration, $\left(c_{\mathrm{tot}}{ }^{*}\right)_{\min }$, on $\mathrm{pH}$. Horizontal line: $c_{\mathrm{tot}}=2\left[\mathrm{Br}_{2}\right.$, sat $]=$ $0.37 \mathrm{M}$.

Variation of this minimal critical value of the total concentration, $\left(c_{\mathrm{tot}}{ }^{*}\right)_{\min }$, as function of $\mathrm{pH}$ is shown in Fig. 1b.

For acidic conditions (relatively low $\mathrm{pH}$ values) this concentration, $\left(c_{\mathrm{tot}} *\right)_{\min }$, approaches to the limit determined by the saturation concentration of solute bromine, $2\left[\mathrm{Br}_{2}\right]_{\mathrm{sat}}=0.37 \mathrm{M}, \mathrm{Eq}(25)$. This behavior may be interpreted on the basis of the distribution of the concentrations as 
functions of the potential for low $\mathrm{pH}$ values below where the $\left[\mathrm{Br}_{2}\right]$ contribution becomes dominant within an intermediate potential range. Thus, for such acidic conditions the variation of the composition of the system depending on the potential, $E$, is crucially different depending on whether the total concentration of $\mathrm{Br}$ atoms, $c_{\mathrm{tot}}$, is lower or higher than its minimal critical value, $\left(c_{\text {tot }}{ }^{*}\right)_{\min }$, as illustrated by horizontal lines $0.2 \mathrm{M}$ and $1 \mathrm{M}$ in Fig. $1 \mathrm{a}$ for $\mathrm{pH}=4$ and $\mathrm{pH}=$ 4.5 .

Increase of $\mathrm{pH}$ leads to higher values of $\left(c_{\mathrm{tot}}{ }^{*}\right)_{\min }$ so that they exceed the saturation limits of $\mathrm{Br}^{-}$ and $\mathrm{BrO}_{3}{ }^{-}$containing solutions both for weakly acidic and alkaline conditions. It means that the liquid bromine phase cannot be formed in this case for any electrode potential, $E$, as it follows from the absence of intersection points between the horizontal lines and the $c_{\text {tot }}{ }^{*}$ graph in Fig. 1a.

2.5 Distribution of concentrations in the presence of the liquid bromine phase

Analysis of the previous section has demonstrated that the liquid bromine can only be formed under sufficiently low $\mathrm{pH}$ values where the horizontal line corresponding to the chosen $c_{\text {tot }}$ value crosses the $c_{\text {tot }}{ }^{*}$ graph for the same $\mathrm{pH}$ value in Fig. 1a (e.g. as the $1 \mathrm{M}$ line for $\left.\mathrm{pH} \leq 4\right)$ in two critical points, $E^{*(1)}$ and $E^{*(2)}$, dependent on both $\mathrm{pH}$ and $c_{\mathrm{tot}}$. Then, liquid bromine, $\mathrm{Br}_{2}{ }^{\text {liq }}$, is present in the system for any potential, $E$, between two intersection points: $E^{*(1)}<E<E^{*(2)}$, while it is absent outside this range.

In the presence of liquid bromine the molecular bromine concentration in aqueous solution, $\left[\mathrm{Br}_{2}\right]$, is always equal to its saturation value, $\left[\mathrm{Br}_{2}\right.$,sat $]$ given by $\mathrm{Eq}(28)$. Therefore, Eqs (15)(17),(20)-(22),(26) may be used again for calculation of all other concentrations in them, $\left[\mathrm{Br}^{-}\right]$, $\left[\mathrm{Br}_{3}{ }^{-}\right],\left[\mathrm{Br}_{5}^{-}\right],[\mathrm{HBrO}],\left[\mathrm{BrO}^{-}\right],\left[\mathrm{BrO}_{3}{ }^{-}\right]$and $\left[\mathrm{Br}_{2}{ }^{\text {vap }}\right]_{\text {sol }}\left(\right.$ i.e. $N\left(\mathrm{Br}_{2}{ }^{\text {vap }}\right)$ via Eq (8)) which are equal to the corresponding critical values for this potential, $E$.

Since within the potential range: $E^{*(1)}<E<E^{*(2)}$ the horizontal line for the chosen $c_{\text {tot }}$ value is above the $c_{\text {tot }} *$ graph (Fig. 1a) it means that $c_{\text {tot }}$ exceeds the sum of all these contributions in Eq (27). As a result, Eqs (7) and (8) give a positive value for the effective concentration of the bromine in its liquid phase, $\left[\mathrm{Br}_{2}{ }^{\text {liq }}\right]_{\mathrm{sol}}, \mathrm{Eq}(8)$ :

$$
\begin{aligned}
& {\left[\mathrm{Br}_{2}{ }^{\text {liq }}\right]_{\mathrm{sol}}=1 / 2\left\{c_{\text {tot }}-\left[\mathrm{Br}^{-}\right]-3\left[\mathrm{Br}_{3}^{-}\right]-5\left[\mathrm{Br}_{5}^{-}\right]-2\left[\mathrm{Br}_{2}\right]-\right.} \\
& \left.-[\mathrm{HBrO}]-\left[\mathrm{BrO}^{-}\right]-\left[\mathrm{BrO}_{3}^{-}\right]-2\left[\mathrm{Br}_{2}{ }^{\mathrm{vap}}\right]_{\mathrm{sol}}\right\}
\end{aligned}
$$

where the effective concentrations of bromine molecules in the vapor and liquid forms $\left[\mathrm{Br}_{2}{ }^{\mathrm{vap}}\right]_{\mathrm{sol}}$ and $\left[\mathrm{Br}_{2}{ }^{\text {liq }}\right]_{\mathrm{sol}}$, are defined by $\mathrm{Eq}(8)$.

2.6 Distribution of concentrations in the absence of the liquid bromine phase 
If the total concentration, $c_{\text {tot }}$, is lower that its critical value for the same $E$ and $\mathrm{pH}$ values, in particular for any potential, $E$, if $c_{\text {tot }}$ is smaller than $\left(c_{\text {tot }}^{*}\right)_{\min }$ for the chosen $\mathrm{pH}$, the liquid bromine phase is absent: $\left[\mathrm{Br}_{2}{ }^{\text {liq }}\right]_{\text {sol }}=0$. Then, the set of 8 equations for 8 unknown concentrations: Eqs (15)-(17),(20)-(22),(26) and the reduced variant of Eq (7):

$\left[\mathrm{Br}^{-}\right]+3\left[\mathrm{Br}_{3}^{-}\right]+5\left[\mathrm{Br}_{5}^{-}\right]+2\left[\mathrm{Br}_{2}\right]+[\mathrm{HBrO}]+\left[\mathrm{BrO}^{-}\right]+\left[\mathrm{BrO}_{3}^{-}\right]+2\left[\mathrm{Br}_{2}{ }^{\text {vap }}\right]_{\text {sol }}=c_{\text {tot }}$

allows one to determine these concentrations for known values of $c_{\mathrm{tot}}, E$ and $\mathrm{pH}$.

In practical terms one can express all concentrations via one of them, e.g. via [Br-] or $\left[\mathrm{Br}_{2}\right]$, with the use of Eqs (15)-(17),(20)-(22),(26) in order to get an algebraic equation for this concentration from $\mathrm{Eq}(30)$ and to find its solution numerically.

\subsection{Graphical illustrations for concentration distributions}

Above procedures for calculation of the concentrations of all components of the Br-containing system as functions of the electrode potential, $E$, have been used for several values of the total concentration, $c_{\text {tot }}=0.2 \mathrm{M}, 0.5 \mathrm{M}$ or $2 \mathrm{M}$, and various acidities: $\mathrm{pH}=2,4,6$ or 8 . Then, the corresponding dependences for the average oxidation degree of $\mathrm{Br}$ atoms, $x$, have been found.

These values of $c_{\text {tot }}$ are chosen to illustrate three characteristic situations: 1) $c_{\text {tot }}=0.2 \mathrm{M}<$ $0.37 \mathrm{M}$ so that liquid bromine phase cannot appear at any $\mathrm{pH}$ and any potential, 2) $\left(c_{\text {tot }}{ }^{*}\right)_{\min }<c_{\text {tot }}$ $=0.5 \mathrm{M}$ for $\mathrm{pH}=2$, i.e. liquid $\mathrm{Br}_{2}$ phase is formed inside a medium range of potentials but its contribution is relatively moderate, 3$)$ the $c_{\text {tot }}$ value is so high $\left(c_{\text {tot }}=2 \mathrm{M}\right)$ that liquid bromine phase is predominant within a medium potential range.

Since effects due to activity coefficients in Eqs (15)-(17),(20)-(22),(26) depend on the particular choice of the background electrolyte the illustrative numerical results below have been obtained for their values equal to 1 .

According to Fig. 1a, all these concentration-dependent effects (for the chosen range, $c_{\text {tot }} \leq 2 \mathrm{M}$ ) are expected only under sufficiently acidic conditions ( $\mathrm{pH}=2$ among the chosen $\mathrm{pH}$ values). As one can see in Fig. 1b the value of the minimal critical total concentration, $\left(c_{\text {tot }}{ }^{*}\right)_{\min }$, increases rapidly within the range of weakly acidic conditions so that already for $\mathrm{pH}=4$ the liquid bromine phase can only exist at the highest total concentration (2 M).

Expressions for calculation of the effective concentration of bromine in the vapor state, $\left[\mathrm{Br}_{2}{ }^{\text {vap }}\right]_{\mathrm{sol}}$, Eqs (8) and (26), contain the ratio of the volumes of these phases, $V^{\text {gas }} / V^{\text {sol }}$. Graphical illustrations are given for its value equal to 0.8. However, this value does not affect markedly other concentrations since values of $\left[\mathrm{Br}_{2}{ }^{\text {vap }}\right]_{\text {sol }}$ turned out to be several orders of magnitude lower than $c_{\text {tot. }}$ 
Fig. 2 shows the results for variation of $\mathrm{x}$ as a function of $E$ for each combination of the $c_{\text {tot }}$ and $\mathrm{pH}$ values. In conformity with the general analysis the value of $x$ tends to -1 or to +5 for sufficiently large negative or positive potentials, respectively, reflecting the predominance of $\mathrm{Br}^{-}$ or $\mathrm{BrO}_{3}{ }^{-}$species in the system. At the same time the shape of the graph within the intermediate potential range is affected by the chosen values of $c_{\text {tot }}$ and especially $\mathrm{pH}$.

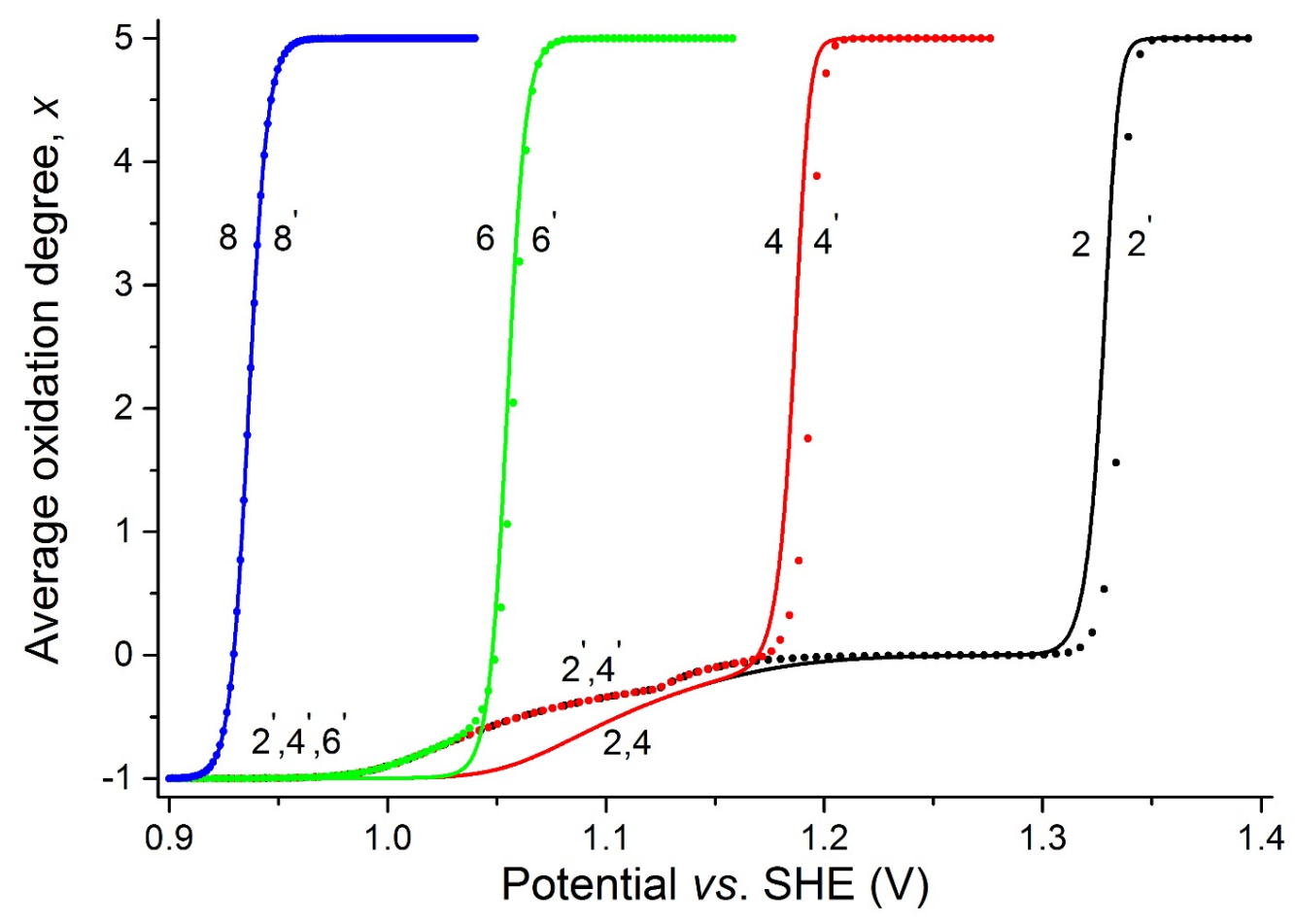

Fig. 2. Dependence of average oxidation charge of $\mathrm{Br}$ atoms on potential, $E$, for various $\mathrm{pH}$ values (indicated at each graph). Solid lines: $c_{\mathrm{tot}}=0.2 \mathrm{M}$ (lines $\left.2,4,6,8\right)$; dotted lines: $c_{\mathrm{tot}}=2 \mathrm{M}$ (lines 2', 4', 6', 8').

Under strongly acidic condition $(\mathrm{pH}=2)$ the graphs show two transitions, from -1 to 0 and from 0 to +5 well separated by a wide interval where the $x$ values are close to 0 , i.e. $\mathrm{Br}$ atom are mostly in the form of bromine species. Variation of the total concentration, $c_{\text {tot }}$, gives a minor change: slightly more extended medium potential interval for larger $c_{\text {tot }}$ values due to a greater stability of $\mathrm{Br}_{2}$ in all forms with respect to both $\mathrm{Br}^{-}$and $\mathrm{BrO}_{3}{ }^{-}$(entropic effect).

For higher $\mathrm{pH}$ values the potential interval of $\mathrm{BrO}_{3}{ }^{-}$formation is shifted rapidly toward less positive potentials. For sufficiently high $\mathrm{pH}$ (6 and especially 8$)$ the transition has the shape of a single wave, its potential being shifted for about $60 \mathrm{mV}$ per $\mathrm{pH}$ unit, in conformity with Eq (15) for the direct transformation between $\mathrm{Br}^{-}$and $\mathrm{BrO}_{3}{ }^{-}$species. The $\mathrm{pH}$ shift of the bromateformation wave is a bit (20\%) stronger for lower $\mathrm{pH}$ (between 4 and 2) since the transition takes place between various forms of $\mathrm{Br}_{2}$ and $\mathrm{BrO}_{3}{ }^{-}$with participation of 6 protons per 5 transferred electrons. Effect of $c_{\text {tot }}$ vanishes for higher $\mathrm{pH}$. 

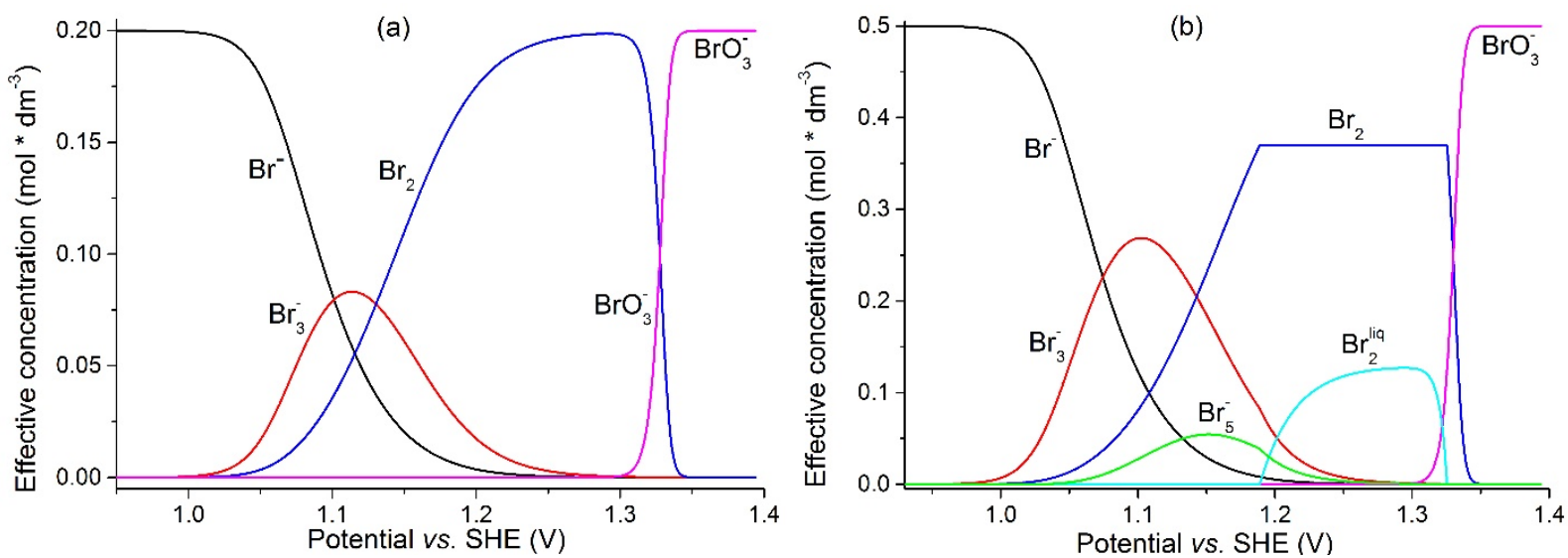

Fig. 3. Distribution of Br-containing components of the system (only principal ones are shown) in terms of $\mathrm{Br}$-atom moles per $\mathrm{dm}^{3}$, i.e. left-side terms in $\mathrm{Eq}(7)$ for each component; $\mathrm{pH}=2$, (a) $c_{\text {tot }}=0.2 \mathrm{M}$, (b) $c_{\text {tot }}=0.5 \mathrm{M}$.
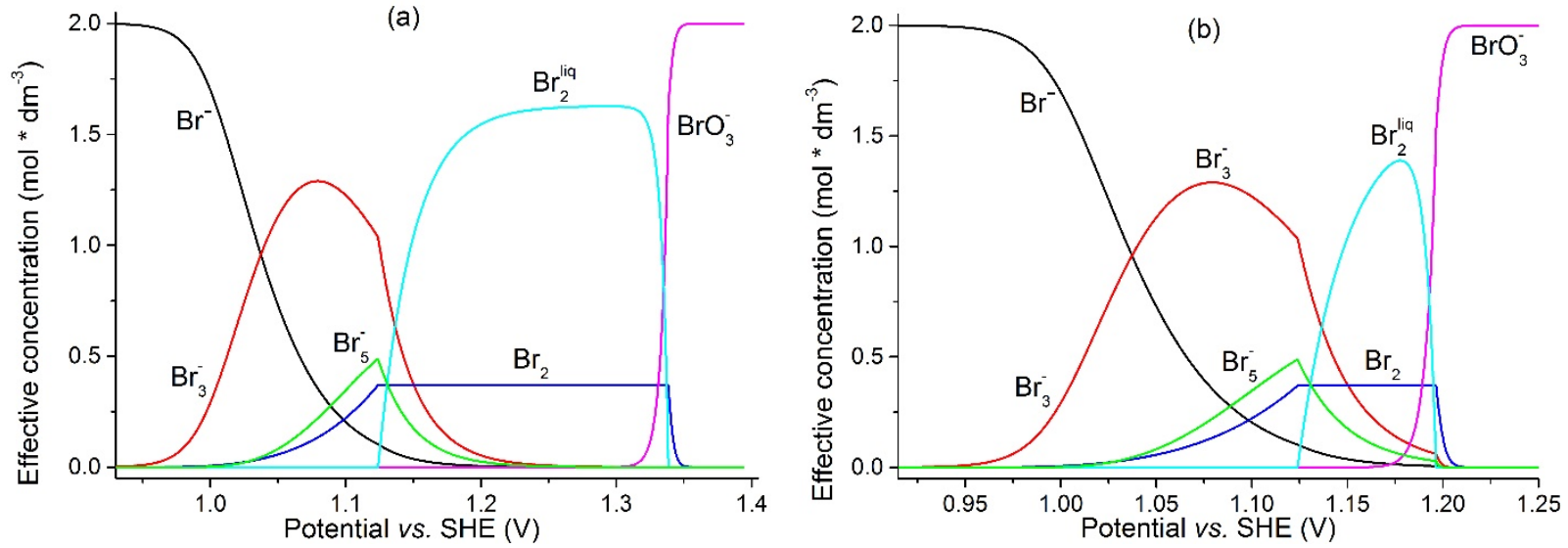

Fig. 4. Distribution of Br-containing components of the system (only principal ones are shown) in terms of $\mathrm{Br}$-atom moles per $\mathrm{dm}^{3}$, i.e. left-side terms in $\mathrm{Eq}$ (7) for each component; $c_{\text {tot }}=2 \mathrm{M}$, (a) $\mathrm{pH}=2$, (b) $\mathrm{pH}=4$.
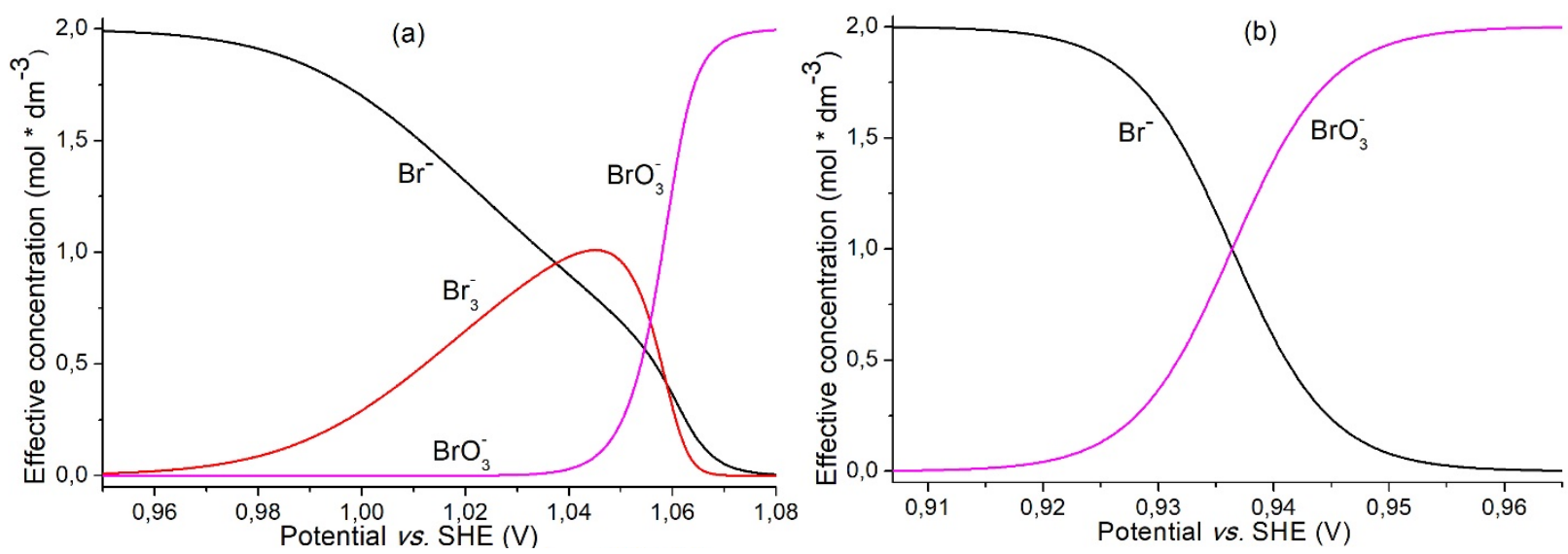

Fig. 5. Distribution of Br-containing components of the system (only principal ones are shown) in terms of Br-atom moles per $\mathrm{dm}^{3}$, i.e. left-side terms in $\mathrm{Eq}(7)$ for each component; $c_{\text {tot }}=2 \mathrm{M}$, (a) $\mathrm{pH}=6$, (b) $\mathrm{pH}=8$. 
Figs. 3-5 provide illustrations for the dependence of concentrations of components (corrected for the number of $\mathrm{Br}$ atoms in the corresponding species, i.e. $n_{\mathrm{i}} c_{\mathrm{i}}$ in $\mathrm{Eq}(6)$ ) on the potential, $E$, for various values of $c_{\text {tot }}$ and $\mathrm{pH}$. Since the number of $\mathrm{Br}$ atoms in some components $\left(\mathrm{Br}_{2}, \mathrm{Br}_{3}{ }^{-}\right.$, etc.) is over 1 all graphs in Figs. 3-5 are plotted with taking this point into account, i.e. they represent terms in Eq (7) including the corresponding stoichiometric coefficients so that their sum is always equal to $c_{\text {tot. }}$

In conformity with graphs for $x$ in Fig. 2, for low $\mathrm{pH}(\mathrm{pH}=2)$ one can notice two separated potential ranges where the composition of the system changes radically (Figs. 3a,b and 4a).

Transition between $\mathrm{Br}^{-}$and $\mathrm{Br}_{2}$ takes place within the interval between $1.0 \mathrm{~V}$ and $1.2 \mathrm{~V}$ for all $c_{\text {tot }}$ values (Figs. 3a,b and 4a), obviously related to the value of the corresponding standard potential, $E_{3}{ }^{0}$, in $\mathrm{Eq}$ (17). The value of the total concentration, $c_{t o t}$, affects both the relative contributions of the solute and liquid forms of $\mathrm{Br}_{2}$ within the medium potential interval (plateau values around $1.3 \mathrm{~V}$ where the contributions of the other components are relatively much smaller) and the composition of the intermediate components (around $1.1 \mathrm{~V}$ ).

For $c_{\text {tot }}=0.2 \mathrm{M}$ (Fig. 3a) liquid bromine is absent at all so that solute $\mathrm{Br}_{2}$ is the only predominant component near $1.3 \mathrm{~V}:\left[\mathrm{Br}_{2}\right] \cong 1 / 2 c_{\text {tot }}$, while contributions of intermediate species (mostly, tribromide) are visible near $1.1 \mathrm{~V}$. For a higher total concentration $\left(c_{\text {tot }}=0.5 \mathrm{M}\right.$, Fig. $\left.3 \mathrm{~b}\right)$ the effective concentration of the liquid bromine, $\left[\mathrm{Br}_{2}{ }^{\text {liq }}\right]_{\text {sol }}$ (about $0.07 \mathrm{M}$ at $E=1.3 \mathrm{~V}$ ) is already comparable with the saturation one of solute bromine: $\left[\mathrm{Br}_{2}\right] \cong 0.185 \mathrm{M}, \mathrm{Eq}$ (28), while the transition between $\mathrm{Br}^{-}$and $\mathrm{Br}_{2}$ effectively takes place via $\mathrm{Br}_{3}{ }^{-}$. For the highest amount of $\mathrm{Br}$ atoms $\left(c_{\text {tot }}=2 \mathrm{M}\right.$, Fig. $\left.4 \mathrm{a}\right)$ the solute bromine retains its saturation concentration within the plateau region so that the contribution of the liquid bromine: $\left[\mathrm{Br}_{2}{ }^{l i q}\right]_{\text {sol }} \cong 1 / 2 c_{\text {tot }}-\left[\mathrm{Br}_{2}\right]_{\text {sat }}$ is dominant there. As for the transition range around $1.1 \mathrm{~V}$, diminution of the $\left[\mathrm{Br}^{-}\right]$concentration is compensated mostly by a rise of the $\left[\mathrm{Br}_{3}^{-}\right]$one, accompanied by relatively smaller contributions of $\left[\mathrm{Br}_{5}^{-}\right]$and $\left[\mathrm{Br}_{2}\right]$. Only around $1.1 \mathrm{~V}$ these variations change abruptly: $\left[\mathrm{Br}_{3}^{-}\right]$and $\left[\mathrm{Br}_{5}^{-}\right]$start their rapid decrease, $\left[\mathrm{Br}_{2}\right]$ rests at its saturation level while the contribution of the liquid bromine increases rapidly, with its further approach to a plateau value.

All dependences of the concentrations on the potential (Figs. 3-5) are given by smoothly varying lines. This behavior is violated in the critical points, $E^{*(1)}$ and $E^{*(2)}$, where the liquid bromine phase just appears or disappears (Figs. $3 \mathrm{~b}$ and $4 \mathrm{a}$ ). For example, at $E=E^{*(1)}$ the rapidly increasing $\left[\mathrm{Br}_{2}\right]$ concentration changes its slope to its zero value (plateau at its saturation level) while the slope of the liquid bromine concentration jumps in the opposite direction: from zero to a finite positive value. Sailing points (jump of the line's slope) are well visible in Fig. 6a for most principal components at $E=E^{*(1)}$, including $\mathrm{Br}_{3}{ }^{-}$and $\mathrm{Br}_{5}{ }^{-}$, while the $\mathrm{Br}^{-}$line seems to be smooth. 
Fig. $6 \mathrm{~b}$ for the logarithmic derivative of $\left[\mathrm{Br}_{2}\right]$ provides an explanation of this observation. The sailing point of this line is less visible since the slope changes between two negative values which are not strongly different from one another.
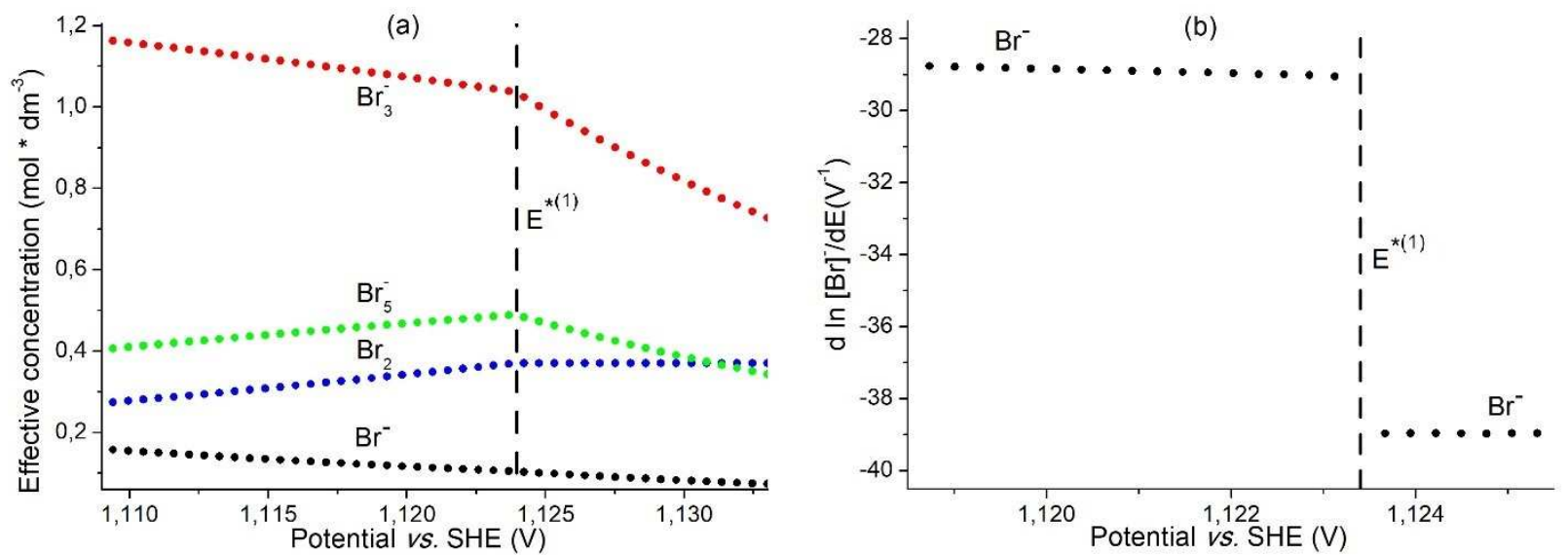

Fig. 6. See Fig. 3. (a) Abrupt changes of slopes of concentration graphs in critical point $\left(E^{*(1)} \cong\right.$ $1.12 \mathrm{~V}) ; \mathrm{pH}=2, c_{\text {tot }}=2 \mathrm{M}$. (b) Logarithmic derivative of bromide concentration, $\mathrm{d} \ln \left[\mathrm{Br}^{-}\right] / \mathrm{d} E$. Vertical dash lines correspond to $E^{*(1)} \cong 1.12 \mathrm{~V}$.

Similar features are characteristic for the second transition where solute and liquid bromine are transformed finally to bromate anion, $\mathrm{BrO}_{3}{ }^{-}$(Figs. 3a,b and 4a). The concentration of the only significant intermediate species, $\mathrm{HBrO}$, gives a noticeable contribution to the total concentration for its lowest value while its effect decreases for higher total concentration $\left(c_{\text {tot }}=0.5 \mathrm{M}\right.$, inset of Fig. 3b) and it is negligible for $c_{\text {tot }}=2 \mathrm{M}$, Fig. 4a). The sailing point behavior is visible again mostly for the solute and liquid bromine concentrations.

In conformity with data in Fig. 2, increase of $\mathrm{pH}$ shifts the $\mathrm{BrO}_{3}{ }^{-}$formation wave toward less positive potentials. For $\mathrm{pH}=4$ this effect diminishes the width of the medium potential interval where the bromine forms give the principal contribution to $c_{t o t}$ (around $1.15-1.20 \mathrm{~V}$ in Fig. $4 \mathrm{~b}$ ). Similar to results for $\mathrm{pH}=2$, tribromide plays an important role as an intermediate species for various total concentrations while a combined effect of $\mathrm{Br}_{3}{ }^{-}, \mathrm{Br}_{5}{ }^{-}$and liquid bromine manifests itself for higher total concentrations (Figs. 4b).

For even higher $\mathrm{pH}$ values (Figs. 5a,b) the contributions of intermediate forms (including $\mathrm{Br}_{2}$ and $\mathrm{Br}_{2}{ }^{\text {liq }}$ ) become small, except for $\mathrm{pH}=6$ and $c_{\text {tot }}=2 \mathrm{M}$ where one can distinguish two transitions: $\mathrm{Br}^{-} / \mathrm{Br}_{3}^{-}$and $\mathrm{Br}_{3} / \mathrm{BrO}_{3}^{-}$(Fig. 5a). These results are obviously in conformity with those in Fig. 2 for the average oxidation degree.

\section{Conclusions}

Performed analysis has provided a complete information on the variation of the equilibrium composition of a Br-containing solution as a function of its redox potential, $E$, for any values of the total concentration of $\mathrm{Br}$ atoms in the solution, $c_{\text {tot }}$, and its $\mathrm{pH}$. It has revealed a dramatic 
change of the evolution of the composition between its maximally reduced and maximally oxidized states depending on the solution $\mathrm{pH}$. Under sufficiently acidic conditions $(\mathrm{pH}=2$ or lower), passage of the positive current through the starting pure bromide system results initially in its transformation into intermediate species, $\mathrm{Br}_{3}^{-}$and $\mathrm{Br}_{5}^{-}$, and then almost completely into bromine molecules in solute and (may be) liquid states (their relative contributions depend on the total $\mathrm{Br}$ atom concentration, $c_{\text {tot }}$ ). Further transition into $\mathrm{BrO}_{3}{ }^{-}$only takes place at significantly higher positive potentials. On the contrary, for neutral or alkaline $\mathrm{pH}$ conditions all these species having intermediate oxidation degrees are practically absent so that the direct transformation between bromide and bromate occurs within a relatively narrow potential range. Besides, higher $\mathrm{pH}$ values result in a strong shift of this transition interval towards lower potentials.

\section{Acknowledgments}

This research is supported by the Russian Ministry of Education and Research (Grant № 14.574.21.0150, UIN RFMEFI57417X0150).

\section{References}

[1]. A. N. Frumkin, G. M. Florianovich, Anion electroreduction, Proc. USSR Acad. Sci. 80 (1951) 907-910.

[2]. G. M. Florianovich, A. N. Frumkin, On the mechanism of electroreduction of anions on a mercury cathode, Russ. J. Phys. Chem. 29 (1955) 1827-1846.

[3]. A. N. Frumkin, N. V. Nikolaeva-Fedorovich, N. P. Berezina, H. E. Keis, The electroreduction of the $\mathrm{S}_{2} \mathrm{O}_{8}{ }^{2-}$ - anion, J. Electroanal. Chem. 58 (1975) 189-201.

[4]. G. N. Botukhova, M. I. Borzenko, O. A. Petrii, Effect of ammonium ions on the electroreduction of anions at a mercury electrode, Russ. J. Electrochem. 40 (2004) 414-419.

[5]. M. Skyllas-Kazacos, C. Menictas, T. M. Lim, Redox flow batteries for medium- to largescale energy storage, Electricity Transmission, Distribution and Storage Systems. Cambridge, Woodhead Publishing Series in Energy (2013) 398-441.

[6]. A. Z. Weber, M. M. Mench, J. P. Meyers, P.N. Ross et al. Redox flow batteries: a review, J. Appl. Electrochem. 41 (2011) 1137-1164.

[7]. K. T. Cho, M. Tucker, A. Weber, A review of hydrogen/halogen flow cells, Energy Techn. 4 (2016) 398-441.

[8]. A. Habib, C. Sou, Analytical review on the trends and present situation of large-scale sustainable energy storage technology, Eur. J. Sustain. Dev. (2018) DOI: $10.20897 /$ ejosdr/86200 
[9]. Yu. V. Tolmachev, M. A. Vorotyntsev, Fuel cells with chemically regenerative redox cathodes, Russ. J. Electrochem., 50 (2014) 403-411.

[10]. Y. V. Tolmachev, A. Piatkivskyi, V. V. Ryzhov, D. V. Konev, M. A. Vorotyntsev, Energy cycle based on a high specific energy aqueous flow battery and its potential use for fully electric vehicles and for direct solar-to-chemical energy conversion, J. Solid State Electrochem. 19 (2015) 2711-2722.

[11]. M. A.Vorotyntsev, A. E. Antipov, D. V. Konev, Bromate anion reduction: novel autocatalytic (EC") mechanism of electrochemical processes. Its implication for redox flow batteries of high energy and power densities, Pure Appl. Chem. 89 (2017) 1429-1448.

[12]. M. A. Vorotyntsev, D. V. Konev, Y. V. Tolmachev, Electroreduction of halogen oxoanions via autocatalytic redox mediation by halide anions: Novel EC" mechanism. Theory for stationary 1D regime, Electrochim. Acta 173 (2015) 779-795.

[13]. A. D. Modestov, D. V. Konev, A. E. Antipov, M. M. Petrov, R. D, Pichugov, M. A. Vorotyntsev, Bromate electroreduction from sulfuric acid solution at rotating disk electrode: experimental study, Electrochim. Acta, 259 (2018) 655-663

[14]. D. V. Konev, A. E. Antipov, M. M. Petrov, M. A. Shamraeva, M. A. Vorotyntsev, Surprising dependence of the current density of bromate electroreduction on the microelectrode radius as manifestation of the autocatalytic redox-cycle $\left(\mathrm{EC}^{\prime \prime}\right)$ reaction mechanism, Electrochem. Comm., 86 (2018) 76-79

[15]. A. D. Modestov, D. V. Konev, O. V. Tripachev, A. E. Antipov, Y. V. Tolmachev, M. A. Vorotyntsev, A hydrogen-bromate flow battery for air-deficient environments. Energy Technol. 6 (2018) 242-245.

[16]. P. Cettou, P. M. Robertson, N. Ibl, On the electrolysis of aqueous bromide solutions to bromate, Electrochim. Acta, 29 (1984) 875-885.

[17]. M. E. H. Bergmann, T. Iourtchouk, J. Rollin, The occurrence of bromate and perbromate on BDD anodes during electrolysis of aqueous systems containing bromide: first systematic experimental studies, J. Appl. Electrochem. 41 (2011) 1109-1123.

[18]. A. Vacca, M. Mascia, S. Palmas, L. Mais, S. Rizzardini, On the formation of bromate and chlorate ions during electrolysis with boron doped diamond anode for seawater treatment. $\mathbf{J}$. Chem. Technol. Biotechnol. 88 (2013) 2244-2251.

[19]. T. Osuga, K. Sugino, Electrolytic Production of Bromates. J. Electrochem. Soc., 1957 104 (1957) 448-451.

[20]. T. Michalowski, Calculation of $\mathrm{pH}$ and potential $\mathrm{E}$ for bromine aqueous solution, $\mathrm{J}$. Chem. Educ. 71 (1994) 560-562. 
[21]. T. Michalowski, A. Lesiak, Acid-base titration curves in disproportionating redox systems, J. Chem. Educ. 71 (1994) 632-636.

[22]. A. M. Michałowska-Kaczmarczyk, A. Spórna-Kucab, T. Michałowski, Formulation of simple electrolytic redox systems according to GATES/GEB Principles, J. Chem. Appl. Chem. Eng. 1:1 (2017) 1-10.

[23]. A. M. Michałowska-Kaczmarczyk, A. Spórna-Kucab, T. Michałowski, Some regularities involved with oxidation number stated in formulation of redox systems according to GATES/GEB Principles, J. Anal. Bioanal. Sep. Tech. 2:2 (2017) 102-110.

[24]. A. M. Michałowska-Kaczmarczyk, A. Spórna-Kucab, T. Michałowski, Generalized Electron Balance (GEB) as the Law of Nature in Electrolytic Redox Systems, in: M.A. Ali Khalid (Eds.), Redox. Principles and Advanced Applications, InTechOpen, Rijeka, 2017, pp. 10-55.

[25]. M. Toporek, A. M. Michałowska-Kaczmarczyk, T. Michałowski, Symproportionation versus disproportionation in bromine redox systems, Electrochim. Acta, 171 (2015) 176187.

[26]. A. M. Michałowska-Kaczmarczyk, A. Spórna-Kucab, T. Michałowski, Oxidation number, oxidant and reductant as derivative concepts within GATES/GEB formulation, J. Chem. Appl. Chem. Eng. 1:2 (2017) 1-7.

[27]. T. Michałowski, A. M. Michałowska-Kaczmarczyk, M. Toporek, Formulation of general criterion distinguishing between non-redox and redox systems, Electrochim. Acta, 112 (2013) 199-211.

[28]. A. J. Bard, L. R. Faulkner, Electrochemical Methods, 2nd ed., J. Wiley \& Sons, Inc. New York, 2000.

[29]. G. L. Soloveichik, Flow Batteries: Current status and trends, Chem. Rev. 115 (2015) $11533-11558$.

[30]. V. Livshits, A. Ulus, E. Peled, High-power $\mathrm{H}_{2} / \mathrm{Br}_{2}$ fuel cell, Electrochem. Comm., 8 (2006) 1358-1362.

[31]. K. T. Cho, P. Ridgway, A. Z. Weber, S. Haussener, V. Battaglia, V. Srinivasan, High performance hydrogen/bromine redox flow battery for grid-scale energy storage J. Electrochem. Soc., 159 (2012) 1806-1815.

[32]. M. C. Wu, T. S. Zhao, H. R. Jiang, Y. K. Zeng, Y. X. Ren, High-performance zinc bromine flow battery via improved design of electrolyte and electrode, J. Power Sources, 355 (2017) 62-68.

[33]. Q. Lai, H. Zhang, X. Li, L. Zhang, Y. Cheng, A novel single flow zinc-bromine battery with improved energy density, J. Power Sources, 235 (2013) 1-4. 
[34]. O. Z. Pavlovic, N. V. Krstajic, M. D. Spasojevic, Formation of bromates at $\mathrm{RuO}_{2} \mathrm{TiO}_{2}$ titanium anode, Surf. Coat. Technol., 37 (1988) 177-183

[35]. W. A. Alves, C. A. Téllez S., O. Sala, P. S. Santos, R. B. Faria, Dissociation and rate of proton transfer of $\mathrm{HXO}_{3}(\mathrm{X}=\mathrm{Cl}, \mathrm{Br})$ in aqueous solution determined by Raman spectroscopy. J. Raman Spectrosc. 32 (2001) 1032-1036.

[36]. G. H. Kelsall, N. J. Welham, M. A. Diaz, Thermodynamics of $\mathrm{Cl}_{-} \mathrm{H}_{2} \mathrm{O}, \mathrm{Br}-\mathrm{H}_{2} \mathrm{O}, \mathrm{I}_{-} \mathrm{H}_{2} \mathrm{O}$, $\mathrm{Au}-\mathrm{Cl}-\mathrm{H}_{2} \mathrm{O}, \mathrm{Au}-\mathrm{Br}-\mathrm{H}_{2} \mathrm{O}$ and $\mathrm{Au}-\mathrm{I}-\mathrm{H}_{2} \mathrm{O}$ systems at 298 K, J. Electroanal. Chem. 361 (1993) $13-24$.

[37]. T. Mussini, P. Longhi, Bromine, in: A. J. Bard (Ed.), Standard potentials in aqueous solutions, 1 ed., Marcel Dekker Inc., New York, 1985, pp. 78-83. 


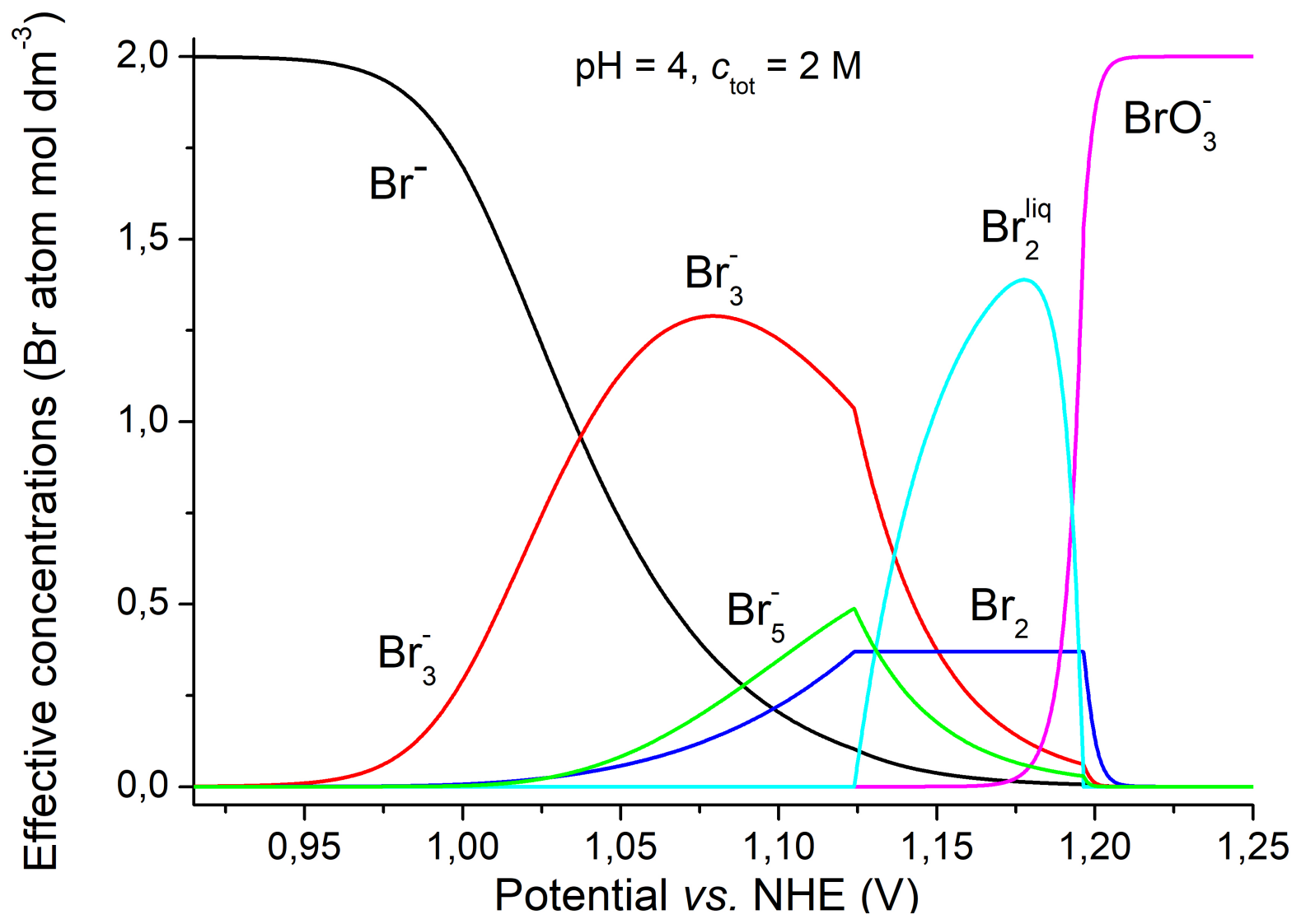

